\title{
Post Translational Modification Analysis
}

National Cancer Institute

\section{Source}

National Cancer Institute. Post Translational Modification Analysis. NCI Thesaurus. Code C18951.

Laboratory procedures used for the analysis of the processing events of a protein after its translation from messenger RNA in order to gain insight into biological function.

These include mass spectrometric peptide sequencing and analysis technologies. 